\title{
Estratégia\&Negócios
}

ISSN 1984-3372

http://www.portaldeperiodicos.unisul.br/index.php/EeN/

\section{A ATIVIDADE INOVADORA EM INDÚSTRIAS DE SANTA MARIA/RS: UM ESTUDO MULTICASOS}

\section{THE INNOVATIVE ACTIVITY IN INDUSTRIES OF SANTA MARIA/RS: A MULTICASE STUDY}

\section{Roberto Schoproni Bichueti}

Mestrando em Administração do Programa de Pós-Graduação em Administração da Universidade Federal de Santa Maria - PPGA/UFSM

E-mail: robertobichueti@hotmail.com

\section{Luciana Aparecida Barbieri da Rosa}

Mestranda do Programa de Pós-Graduação em Administração

E-mail: lucianaaparecidabarbieri@yahoo.com.br

\section{Márcia Zampieri Grohmann}

Professora Adjunta do Departamento de Ciências Administrativas

E-mail: marciazg@gmail.com

\section{Clandia Maffini Gomes}

Professora Adjunta do Departamento de Ciências Administrativas

E-mail: clandiamg@gmail.com

\section{Jordana Marques Kneipp}

Doutoranda do Programa de Pós-Graduação em Administração

E-mail: jordana.mk@gmail.com

Recebido em 13/11/2012. Aprovado em 22/08/2013. Disponibilizado em 30/08/2013. Avaliado pelo Sistema double blind review

R. eletr. estrat. neg., Florianópolis, v.6, n.2, p. 284-312, mai./ago. 2013

http://portaldeperiodicos.unisul.br/index.php/EeN/index
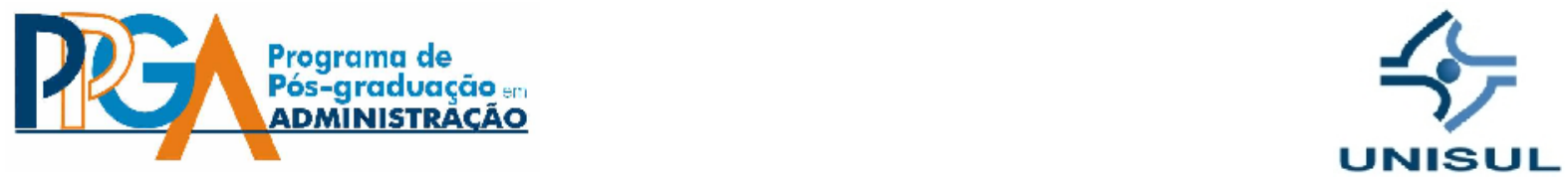

CCopyright 2008 UNISUL-PPGA/Estratégia e Negócios. Todos os direitos reservados. Permitida citação parcial, desde que identificada a fonte. Proibida a reprodução total. Em caso de dúvidas, consulte o editor: ademar.unisul@gmail.com; (48) 3229-19 


\section{RESUMO}

Este estudo tem como objetivo identificar a atividade inovadora em indústrias situadas no Distrito Industrial de Santa Maria/RS. Para tanto, desenvolveu-se uma pesquisa descritiva, de abordagem qualitativa, operacionalizada por um estudo de casos múltiplos. Utilizou-se o framework proposto por Sawhney, Wolcott e Arroniz (2006), denominado Radar da Inovação, que aborda as oportunidades de inovação em doze dimensões: oferta, plataforma, soluções, clientes, relacionamento com o cliente, captura de valor, processos, organização, cadeia de fornecimento, presença, networking e marca. Identificou-se a presença de práticas inovativas em todas as dimensões propostas no modelo conceitual, bem como foi possível perceber como se dá o desenvolvimento de tais atividades em cada uma das empresas estudadas. Além disto, evidenciou-se a importância da inovação para estas indústrias e as dificuldades por elas enfrentadas durante o processo.

Palavras-Chave: Inovação. Indústria. Maturidade Inovadora.

\section{INTRODUÇÃO}

As organizações são instigadas a estarem em constante adaptação em decorrência do ambiente mutável no qual estão inseridas. Dessa forma, a inovação consiste em uma estratégia fundamental na determinação da competitividade organizacional e adquire maior importância de acordo com a turbulência ambiental. A inovação é considerada, neste contexto, a principal característica para a competitividade e para o desempenho econômico da empresa. É através da adoção de novas práticas, processos ou do desenvolvimento de novos produtos e serviços que as empresas buscam destaque nos mercados em que atuam (CHRISTENSEN, 2001; MOTTA, 2001).

A inovação não está restrita somente ao lançamento de novos produtos e serviços. De acordo com o Manual de Oslo (2005), que traz uma definição de inovação amplamente utilizada, as inovações podem ser divididas em quatro tipos: inovações de produto, de processo, organizacionais e de marketing. Entretanto, dive rsas pesquisas apresentam outras maneiras de inovar e se destacar nos mercados onde as empresas 
atuam. Nesse sentido, cita-se a proposta de Sawhney, Wolcott e Arroniz (2006) que consideram a inovação como a criação de valor para os clientes e para a empresa através da mudança criativa em uma ou mais dimensões do sistema empresarial. Com o intuito de propor um modelo conceitual para a inovação, os autores desenvolveram um framework denominado "Radar da Inovação", uma ferramenta com 12 dimensões por meio das quais as empresas podem identificar oportunidades de inovação.

Inseridas em um ambiente específico, com a necessidade de inovar e se desenvolver, estão as indústrias localizadas no Distrito Industrial de Santa Maria/RS. Projetado pelo governo do Estado do Rio Grande do Sul, há 34 anos, o Distrito Industrial sempre esteve, intrinsecamente, ligado às questões do desenvolvimento industrial do município. Segundo a Associação Distrito Vivo (2011), entidade que congrega as empresas lá situadas, existem, atualmente, 25 empresas instaladas em uma área total de 394ha. Entre os desafios enfrentados pelas indústrias, está a busca pela inovação, já que esse é um fator determinante para o sucesso empresarial.

Tendo em vista a busca pela competitividade e a importância da inovação neste processo, surgem os seguintes questionamentos: as indústrias de Santa Maria/RS adotam práticas inovativas em seus processos? A inovação está presente nas estratégias e nas operações destas empresas? Dessa forma, surge o seguinte problema de pesquisa: qual a atividade inovadora das indústrias do Distrito Industrial de Santa Maria/RS?

Inserido no contexto supracitado, o presente trabalho tem o objetivo de identificar a atividade inovadora em indústrias situadas no Distrito Industrial de Santa Maria/RS. Para tal, desenvolveu-se uma pesquisa utilizando-se as doze dimensões pertencentes ao framework proposto por Sawhney, Wolcott e Arroniz (2006). Assim, o estudo está estruturado da seguinte maneira: primeiramente será apresentada uma revisão teórica, que trata dos aspectos que envolvem, essencialmente, os aspectos referentes à inovação e, em especial, na descrição do modelo conceitual utilizado; em seguida, descrevese os aspectos metodológicos observados na construção deste estudo; e, por fim, apresentam-se os resultados obtidos nesta pesquisa e as considerações finais. 


\section{REFERENCIAL TEÓRICO}

A inovação, segundo Schumpeter (1985), é um fenômeno fundamental para o desenvolvimento econômico. De acordo com o autor, é através das mudanças provocadas pela inovação que o ciclo econômico sai de seu estado de equilíbrio, denominado fluxo circular, gerando lucro para a empresa inovadora e o desenvolvimento econômico. Essa mudança se dá por causa de rupturas do equilíbrio, tal qual a quebra de um paradigma. Schumpeter (1985) sugere, ainda, que é por meio da inovação que as empresas renovam a sua base de ativos e oportuniza a sustentabilidade da competitividade econômica. As inovações são introduzidas pelos empresários e caracterizam-se pelo grande poder de impacto e de disseminação sobre o conjunto da economia.

Bessant e Tidd (2009) consideram a inovação uma questão de sobrevivência, ou seja, uma necessidade imposta às empresas para se manterem competitivas nos mercados onde estão inseridas. De fato, com o acesso à informação por parte dos consumidores e a imensa quantidade de oferta de produtos e serviços, é temerário para uma organização não pensar em maneiras de proporcionar novas alternativas, sejam estas ligadas diretamente aos produtos e serviços, ou inseridas nos processos, proporcionando assim maior valor para o cliente. Sem que isto aconteça, é muito provável que a empresa seja superada por seus concorrentes, devido à competitividade existente atualmente. Por outro lado, os autores consideram a inovação como uma oportunidade para as empresas, pois ela está estritamente relacionada com o crescimento. Assim, a inovação é orientada pela "habilidade de fazer relações, de visualizar oportunidades e tirar vantagem das mesmas." (BESSANT; TIDD, 2009, p. 22).

Segundo os autores (BESSANT; TIDD, 2009), a gestão da inovação está centrada em três fatores principais: (1) a geração de novas ideias, (2) a seleção estratégica delas, a fim de que se opte por investir nas mais promissoras e, por fim, (3) a implementação, tornandoa um produto, serviço ou processo acabado e disponível. Para tanto, o sucesso desse processo depende de dois ingredientes principais: os recursos (pessoas, conhecimento, financeiros, entre outros) e a capacidade da organização de geri-los. 
Visando a contribuir na definição desses conceitos, a $\operatorname{OCDE}(2009$, p. 2) define inovação como "a implementação de um novo ou da significativa melhoria do produto (bem ou serviço), ou um processo, um novo método de marketing, ou um novo método organizacional nas práticas de negócios, a organização do trabalho ou as relações externas."

Muitos autores, ao buscar estabilidade nos resultados empíricos das pesquisas sobre inovação, introduziram subteorias de inovação organizacional. Passou-se a distinguir as inovações tecnológicas das administrativas, as inovações radicais das incrementais e as inovações de produto das de processo. A necessidade dessa diferenciação se dá para que as organizações possam diferenciar os tipos de inovação aos quais estão mais propícias, no intuito de ajustar o comportamento organizacional e delimitar pontos fortes e fracos no seu desenvolvimento (DAMANPOUR, 1991).

Schumpeter (1985) se refere às inovações radicais como àquelas capazes de produzir um grande impacto econômico ou mercadológico, em detrimento das inovações de ordem incremental e os aprimoramentos técnicos de ordem contínua.

De acordo com o Manual de Oslo (2005), as inovações podem ser divididas em quatro tipos: inovações de produto, de processo, organizacionais e de marketing. Inovação de produto é a introdução de um bem ou serviço novo ou significativamente melhorado no que diz respeito a suas características ou usos previstos. A inovação de processo é a implementação de um método de produção ou de distribuição novo ou significativamente melhorado e compreende mudança significativa em técnicas, equipamentos e/ou softwares. A inovação de marketing é a implementação de um novo método de marketing com mudanças significativas na concepção do produto ou em sua embalagem, no posicionamento do produto, em sua promoção ou na fixação de preços. Por fim, a inovação organizacional é a implementação de um novo método organizacional nas práticas de negócios da empresa, na organização do seu local de trabalho ou em suas relações externas.

Kemp, Smith e Becher (2000) afirmam que a inovação se traduz em um fenômeno multifacetado, que tem como característica principal uma complexidade de interrelações entre pessoas e instituições, envolvendo de um lado, novas ideias e resoluções de problemas, podendo ser vista em termos de criatividade e esforço intelectual, e de outro, recursos financeiros e materiais, frequentemente em larga proporção e em condições 
incertas, com elevados riscos. Corroborando, Tidd, Bessant e Pavitt (2005) enfocam que a inovação deve ser resultado de esforços coletivos e contínuos de todas as áreas da empresa, não ficando somente sob a responsabilidade do departamento de Pesquisa e Desenvolvimento (P\&D).

Nesse contexto, Sawhney, Wolcott e Arroniz (2006) consideram que a inovação não está restrita, como muitas vezes é associada, somente ao lançamento de novos produtos ou na atividade de Pesquisa e Desenvolvimento. Para os autores, inovação é a criação de valor para os clientes e para a empresa através da mudança criativa em uma ou mais dimensões do sistema empresarial.

Nesse sentido, os autores desenvolveram um framework denominado "Radar da Inovação", uma ferramenta com dimensões por meio das quais as empresas podem identificar oportunidades de inovação. Ancorado sobre quatro principais dimensões (oferta, clientes, processos e presença), além de outras oito (plataforma, soluções, relacionamento com o cliente, captura de valor, organização, cadeia de fornecimento, networking e marca), o modelo compreende 12 dimensões detalhadamente descritas no Quadro 1, a seguir

Quadro 1 - As doze dimensões da inovação

\begin{tabular}{|c|c|}
\hline Dimensões & Definições \\
\hline Oferta & Desenvolver novos produtos e serviços inovadores. \\
\hline Plataforma & $\begin{array}{l}\text { Utilizar componentes comuns ou módulos de produção na criação de diversos } \\
\text { produtos. }\end{array}$ \\
\hline Soluções & Criar oferta integrada e customizada para resolver problemas dos consumidores. \\
\hline Clientes & Identificar necessidades não atendidas dos consumidores ou novos segmentos. \\
\hline $\begin{array}{l}\text { Relacionamento } \\
\text { com o cliente }\end{array}$ & Redesenhar a interação com os clientes, em todos os pontos e momentos de contato. \\
\hline Captura de valor & Redefinir a forma como a empresa capta valor ou novas formas de receita inovadoras. \\
\hline Processos & Redesenhar os processos operacionais para melhor eficiência e eficácia. \\
\hline Organização & Mudar forma, função ou atividades da empresa. \\
\hline $\begin{array}{l}\text { Cadeia de } \\
\text { fornecimento }\end{array}$ & Pensar alternativas de terceirização e gestão da cadeia de fornecimento. \\
\hline Presença & $\begin{array}{l}\text { Criar novos canais de distribuição e localização, incluindo locais onde a oferta pode } \\
\text { ser comprada ou utilizada pelos clientes. }\end{array}$ \\
\hline Networking & Criar rede de relacionamento inteligente com oferta integrada. \\
\hline Marca & Alavancar o uso da marca em novos domínios. \\
\hline
\end{tabular}

Fonte: Baseado em Sawhney, Wolcott e ArronizArroniz (2006).

Assim, o "Radar da Inovação" proporciona, segundo Sawhney, Wolcott e Arroniz (2006), uma orientação através de 12 maneiras para inovar, criando valor para os R. eletr. estrat. neg., Florianópolis, v.6, n.2, p. 284-312, mai./ago. 2013 
consumidores, além de uma importante ferramenta para a avaliação do comportamento inovativo.

A partir do aporte teórico apresentado, pode-se avançar em direção ao método do estudo, onde se apresenta a classificação da pesquisa e os procedimentos adotados.

\section{MÉTODO DO ESTUDO}

O presente estudo caracteriza-se, quanto à abordagem, como qualitativo. Para Richardson (1999), as investigações que se voltam para uma análise qualitativa têm como objeto situações complexas ou estritamente particulares. Segundo Godoy (1995), nos estudos qualitativos um fenômeno pode ser melhor compreendido no contexto onde ocorre e do qual é parte, sendo analisado em uma perspectiva integrada.

Quanto à natureza, a pesquisa classifica-se como descritiva, que visa a identificar, descrever e analisar a atividade inovadora das empresas do Distrito Industrial de Santa Maria. Para Triviños (1987), este tipo de estudo pretende descrever os fatos e fenômenos de determinada realidade.

Para o desenvolvimento da pesquisa, utilizou-se o método de estudo de caso. De acordo com Yin (2001), é uma estratégia de pesquisa empírica que investiga um fenômeno contemporâneo dentro de um contexto da vida real, quando a fronteira entre o fenômeno e o contexto não é claramente evidente e onde múltiplas fontes de evidência são utilizadas. Dessa forma, trata-se de um estudo de casos múltiplos, que, de acordo com Gil (2007), consiste em um estudo profundo e exaustivo de poucos objetos, de maneira que permita o seu detalhado conhecimento.

O estudo possui como unidades de análise as indústrias do Distrito Industrial de Santa Maria/RS. Projetado pelo governo do Estado do Rio Grande do Sul, há 34 anos, o Distrito Industrial de Santa Maria, que atualmente possui 25 empresas, sempre esteve, intrinsecamente, ligado às questões do desenvolvimento industrial do município. Em 2004, surgiu, através da união das empresas nele instaladas, a Associação Distrito Vivo, que está fortemente atrelado ao uso e à melhoria da infraestrutura do município. 
Entre as empresas pertencentes a Associação Distrito Vivo, foram escolhidas, por conveniência, oito empresas instaladas no Distrito Industrial de Santa Maria, denominadas, para fins deste estudo, ordenadamente de A até H. Esse procedimento foi adotado para garantir a privacidade das empresas. Da mesma forma, todos os nomes e marcas citadas durante as entrevistas foram omitidos na apresentação dos resultados.

A coleta de dados da pesquisa se deu por meio de múltiplas evidências, entre as quais se destaca a realização de entrevistas semiestruturadas com os gestores das empresas pesquisadas. As entrevistas foram realizadas do dia 1 o ao dia 10 de novembro de 2011 , com visita dos pesquisadores às empresas participantes. As informações obtidas por meio das entrevistas foram complementadas por evidências obtidas através da pesquisa em dados secundários disponibilizados pelas empresas e observação dos pesquisadores.

O protocolo de entrevista foi elaborado a partir das 12 dimensões da inovação, conforme o modelo conceitual proposto por Sawhney, Wolcott e Arroniz (2006), permitindo avaliar a atividade inovadora das organizações de pequeno, médio e grande porte. Conforme já descrito no referencial teórico deste estudo, o modelo proposto pelos autores compreende as variáveis: oferta, plataforma, soluções, clientes, relacionamento com o cliente, captura de valor, processos, organização, cadeia de fornecimento, presença, networking e marca.

Para o estudo de caso, Yin (2001) destaca que o objetivo final da análise é o de tratar as evidências de forma adequada para se obter conclusões analíticas convincentes e eliminar interpretações alternativas. Assim, os dados foram interpretados com base nos pressupostos teóricos, comparando os dados empíricos com padrões previstos no modelo conceitual proposto por Sawhney, Wolcott e Arroniz (2006). Adotou-se os procedimentos de preparação e análise temática dos resultados indicados por Coffey e Atkinson (1996). Assim, as entrevistas foram transcritas e codificadas, de acordo com as variáveis constantes no modelo teórico. Por fim, as evidências foram analisadas separadamente, de acordo com cada uma das dimensões. A partir da caracterização do estudo, pode-se apresentar a análise dos resultados. 


\section{APRESENTAÇÃO E ANÁLISE DOS RESULTADOS}

Este capítulo apresenta a análise dos resultados obtidos na pesquisa. Inicialmente são apresentadas o perfil das empresas pesquisadas. Em seguida, apresenta-se a discussão em relação às 12 dimensões do modelo proposto por Sawhney, Wolcott e Arroniz (2006) para a inovação e a sua aplicação nas empresas entrevistadas. Em seguida, de maneira complementar, é possível identificar as dificuldades enfrentadas pelas empresas no processo de inovação.

\subsection{CARACTERIZAÇÃO DAS EMPRESAS}

O quadro 2, a seguir, apresenta a caracterização das empresas analisadas neste estudo.

Figura 2 - Caracterização das Empresas (estrutura)

\begin{tabular}{|c|c|c|c|c|c|c|c|}
\hline & & & & & Transformaç & & \\
\hline A & 2004 & Privado & $\begin{array}{l}\text { Micro } \\
\text { empresa }\end{array}$ & 12 & $\begin{array}{l}\text { ão de } \\
\text { termoplástic }\end{array}$ & Proprietário & 20 \\
\hline & & & & & $\begin{array}{l}\text { o } \\
\text { Fabricação }\end{array}$ & & \\
\hline B & 1980 & Privado & $\begin{array}{l}\text { Micro } \\
\text { empresa }\end{array}$ & 9 & $\begin{array}{l}\text { de móveis } \\
\text { sobre } \\
\text { medida }\end{array}$ & Sócio & 37 \\
\hline & & & & & Fabricação & Coordenado & \\
\hline C & 1980 & Privada & $\begin{array}{l}\text { Grande } \\
\text { empresa }\end{array}$ & 750 & $\begin{array}{l}\text { e } \\
\text { distribuição } \\
\text { de bebidas }\end{array}$ & $\begin{array}{l}\text { r de } \\
\text { propaganda } \\
\text { e promoção }\end{array}$ & 6 \\
\hline D & 1969 & Privada & $\begin{array}{l}\text { Média } \\
\text { empresa }\end{array}$ & 170 & $\begin{array}{l}\text { Fabricação } \\
\text { de massas e } \\
\text { biscoitos }\end{array}$ & Sócio & 42 \\
\hline E & 1998 & Privada & $\begin{array}{l}\text { Pequena } \\
\text { empresa }\end{array}$ & 200 & $\begin{array}{l}\text { Indústria de } \\
\text { panificação }\end{array}$ & $\begin{array}{l}\text { Gerente } \\
\text { administrati } \\
\text { vo }\end{array}$ & 11 meses \\
\hline $\mathbf{F}$ & 1991 & Privada & $\begin{array}{l}\text { Pequena } \\
\text { empresa }\end{array}$ & 12 & $\begin{array}{l}\text { Fabricação } \\
\text { de sistemas } \\
\text { de irrigação }\end{array}$ & $\begin{array}{l}\text { Engenheiro } \\
\text { agrônomo }\end{array}$ & 20 \\
\hline G & 1989 & Privada & $\begin{array}{l}\text { Micro } \\
\text { empresa }\end{array}$ & 22 & $\begin{array}{l}\text { Refeições } \\
\text { coletivas e }\end{array}$ & Gerente & 12 \\
\hline
\end{tabular}




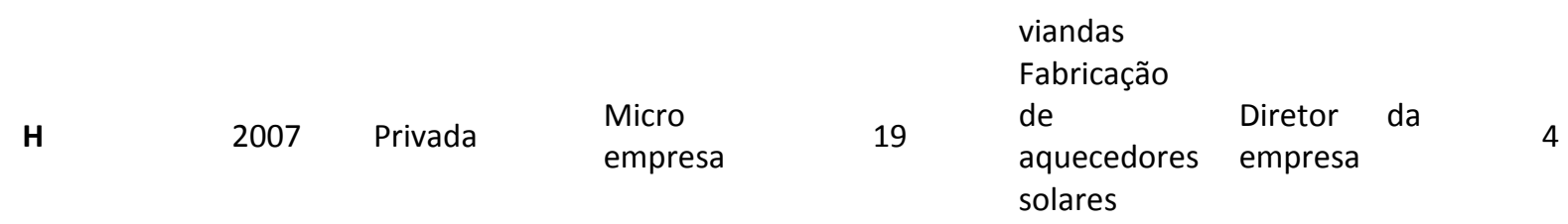

Fonte: Dados da pesquisa, 2013.

Descritas as características das empresas, pode-se avançar para a análise das dimensões da inovação nestas indústrias.

\subsection{AS DIMENSÕES DA INOVAÇÃO}

Conforme o objetivo proposto, esta pesquisa tem o intuito de avaliar as atividades inovadoras das indústrias escolhidas, de acordo com o modelo proposto por Sawhney, Wolcott e Arroniz (2006). Desta forma, os resultados descritos a seguir passam pela análise das doze dimensões proposta pelos autores de acordo com as realidades encontradas nas organizações.

\subsubsection{Oferta}

Esta dimensão está relacionada à oferta por parte das empresas de produtos ou serviços novos. De acordo com Sawhney, Wolcott e Arroniz (2006), a inovação, nesta categoria, requer o desenvolvimento e lançamento de novos produtos e/ou serviços, gerando valor ao cliente.

Na maior parte das empresas analisadas, tem ocorrido o lançamento de novos produtos e serviços nos últimos anos. Isto pôde ser identificado nas empresas A, B, D, F, G e $H$, sendo que, na maioria dos casos, este processo está associado à identificação das necessidades dos clientes e das oportunidades de mercado, na busca da diferenciação. Destaca-se, também, que na maioria dessas empresas existem pessoas responsáveis pelo desenvolvimento e lançamento de novos produtos. Segundo o diretor da Empresa $\mathrm{H}$ : 
de pequeno porte, e possibilidade de trabalhar com fotovoltaicos. [...] Então, as inovações, ou os novos produtos, as novas estratégias, são em cima do que o mercado diz.

O processo de desenvolvimento de novos produtos não ocorre da mesma forma que as demais quando consideradas as empresas C e E. Na empresa E, a oferta de novos produtos não é a prioridade, devido a decisões internas de priorizar outros investimentos, conforme afirma o gerente comercial da empresa:

A gente se policia, pois dentro da produção o pessoal sempre está querendo lançar algo novo. Mas hoje está travado, pois dentro do planejamento estratégico foram definidas datas para iniciar-se um processo organizado, correto, para o lançamento de novos produtos e criar produtos. Então é isto que está sendo desenvolvido. Provavelmente em 2012 o projeto comece a andar de maneira certa e criteriosa.

No caso da empresa $C$, este processo é diferente, pois trata-se de uma franquia e, dessa forma, não é possível que novos produtos sejam aqui desenvolvidos. Porém, a franqueadora desta empresa está constantemente lançando novos produtos, em um processo que passa pela atuação dos franqueados e, conforme afirma o coordenador de promoção e propaganda da empresa, isto foi visto como uma oportunidade de negócio pela empresa C:

\begin{abstract}
A franqueadora pega regiões piloto para lançar novos produtos, geralmente ela lança em grandes centros, (durante) dois a três meses, para testar pra ver se vai lançar no restante do Brasil. Só que nós, há uns três anos atrás, paramos e vimos uma oportunidade para nós, testando em nossas regiões, em todas as nossas cidades, como em Passo Fundo e Santa Maria, são polos que atraem pessoas de todo Brasil, então é muito bom, pra nós testar produtos aqui. [...] Assim, quando teve a oportunidade de lançar o [Produto $\mathrm{x}$ ] que é uma água saborizada, a gente foi a primeira franquia a lançar, quando teve a oportunidade de lançar o (produto y), que é o achocolatado da franqueadora, nós fomos a primeira a lançar [...] e assim a gente tenta, com todos os produtos, quando a [Franqueadora] decide, vamos testar este produto no Brasil, a gente tenta testar primeiro na nossa região.
\end{abstract}

Tais evidências, em relação ao desenvolvimento de novos produtos e serviços, de acordo com Bessant e Tidd (2009), estão estritamente ligadas à inovação. Isto porque, segundo os autores, esta atividade oferece como principal contribuição o aumento da diferenciação de mercado, conforme evidenciado pelos participantes da pesquisa. 


\subsubsection{Plataforma}

De acordo com o modelo proposto por Sawhney, Wolcott e Arroniz (2006), inovar na dimensão plataforma refere-se ao uso de um conjunto de componentes comuns, ou métodos de montagem do tipo modular, na construção de diversos produtos. De acordo com Bachmann e Destefani (2008), entende-se que a habilidade em usar a mesma plataforma para oferecer um maior número de produtos reflete em uma maior capacidade inovadora.

Entre as empresas analisadas, as empresas B, C, D, F e $\mathrm{H}$ afirmam adotar plataformas no processo produtivo de alguns produtos, refletindo, assim, em uma maior capacidade de inovação. De acordo com o consultor da empresa F, "os componentes são sempre os mesmos, mas acontece muito de se ter vários componentes que se encaixam em vários sistemas".

Diante do contexto, o diretor da Empresa $\mathrm{H}$ afirma: "O coletor solar. Ele faz parte de um conjunto, outro conjunto, outro. O reservatório utilizado em um conjunto de aquecedor solar, ele é o mesmo, mudando pequenos detalhes, dentro de um aquecedor elétrico."

Por outro lado, as empresas A, E e G afirmam não adotar tais práticas, pois, de certa forma, não se adéquam aos seus processos produtivos.

\subsubsection{Soluções}

Conforme Sawhney, Wolcott e Arroniz (2006), uma empresa cria soluções para os clientes quando integra e combina produtos, serviços e informações para resolver algum problema ou necessidade do consumidor. Dessa forma, soluções inovadoras criam valor para o cliente.

Foi possível observar a criação de soluções para os clientes na grande maioria das empresas, a exemplo do relato do coordenador de propaganda e promoção da Empresa C: 
[...] muita coisa que a gente oferece para o cliente, desde a geladeira, que é um empréstimo em comodato, conjuntos de mesas e cadeiras, as fachadas, que a gente auxilia eles, mas acho que o que é relevante pra nós é fazer atividade que gerem vendas para eles, que vão gerar receita pra eles.

Na Empresa $H$, esta dimensão é muito trabalhada, sempre objetivando às soluções de problemas dos clientes. Segundo o diretor da empresa, isto faz parte do grupo a qual a empresa pertence: "se o cliente diz que precisa de uma coisa... não vai ir ninguém e dizer "não dá". Isso é uma filosofia. Depois de uma tentativa, aí pode-se dizer "não deu". Mas alguém vai tentar fazer". Somente na Empresa A este processo não foi identificado de maneira sistemática.

Criar soluções para os clientes, segundo Bachmann e Destefani (2008), também pode compreender o desenvolvimento de produtos complementares, que possam agregar valor e gerar uma nova oportunidade de negócio, algo observado na maior parte das empresas consultadas. Corroborando, a gerente da empresa G afirma: "a gente atende as FASES, antigas FEBENs. Para eles, a gente tem uma dieta hipocalórica ou dieta pra diabético. Pra FASE a gente faz. Às vezes, é para um só." Neste sentido, fica evidente a preocupação da empresa em atender às necessidades específicas de determinados clientes, desenvolvendo soluções customizadas por meio da integração de produtos e serviços oferecidos.

\subsubsection{Clientes}

Inovar na dimensão dos clientes, conforme o modelo proposto por Sawhney, Wolcott e Arroniz (2006), está associado a identificar as necessidades e os desejos e, a partir daí, desenvolver novos produtos e/ou serviços. Além disso, compreende a busca por novos clientes.

Entre as empresas analisadas, foi observada uma preocupação em atender às necessidades e aos desejos dos consumidores. Todas as empresas afirmaram levar em consideração as necessidades dos clientes, a exemplo do diretor da Empresa $\mathrm{H}$ :

[...] com certeza, porque o produto é desenvolvido para atender algumas necessidades. Então se nós não levarmos em conta a opinião do cliente, que é quem vai usufruir desse produto, [...] pois não se desenvolve o produto em cima de um sonho. 
O proprietário da Empresa B fala sobre um exemplo em que isto ocorreu na prática:

\begin{abstract}
Nós desenvolvemos a cadeira empilhada de madeira, até então só tinha a cadeira empilhada de ferro ou de plástico de PVC e hoje nós temos a cadeira empilhada de madeira, [...] dá para empilhar até dez cadeiras.[...] O cliente solicitou, nós aceitamos o desafio, nos envolvemos [...] e desenvolvemos a cadeira pro cliente."
\end{abstract}

Porém, em algumas empresas, esta preocupação não se reflete na concepção de novos produtos, o que, de certa forma, contradiz o discurso anterior. Embora o diretor da Empresa $D$ oferta produtos de alta qualidade, para atender às necessidades dos consumidores, o processo de desenvolvimento dos produtos não tem levado em consideração as contribuições dos clientes: "Não, veio de nossa iniciativa de desenvolver um produto novo, com o objetivo de agregar no teu mix, então pra ti ter um mix melhor, pra ti ter mais participação no mercado."

Notou-se, também, que a opinião dos clientes foi relevante não somente no desenvolvimento de novos produtos, mas para a melhoria no processo de fabricação deles. Um exemplo desta evidência está no relato do coordenador de propaganda e promoção da Empresa C:

Então, por exemplo, nos estávamos com uma máquina que não estava com a regulagem mais adequada, porque nós trocamos o tamanho da tampa, Então, assim, o toque dela estava com uma variação muito grande. E isso como é que a gente foi perceber? em função da reclamação dos clientes, muita gente começou a reclamar que estava sem gás no refrigerante, e o gás ele perde ou no pet ou na rolha, como a gente chama a tampa. Em cima disso foram tomadas diversas providencias na linha de produção e corrigiram isso, baixaram esse índice de mais de $30 \%$.

O resultado aqui descrito vem ao encontro de diversas pesquisas que colocam os consumidores como uma das principais fontes externas de informação da inovação. Atender às necessidades dos clientes, conforme evidenciado nas práticas destas indústrias, colaboram para a atividade da inovação (SUGAHARA; JANNUZZI, 2005; GOMES; KRUGLIANSKAS, 2009; IBGE, 2010).

\title{
4.2.5 Relacionamento com os clientes
}


Esta dimensão leva em consideração a experiência com o cliente, ou seja, como se dá o relacionamento da empresa com seus consumidores. De acordo com Sawhney, Wolcott e Arroniz (2006), inovar nesta dimensão requer um repensar da relação com os clientes, proporcionando uma maior proximidade destes, seja na criação de novos canais ou forma de se comunicar.

Nesse sentido, pôde-se observar um esforço bastante grande nas empresas para melhorar o relacionamento com os seus clientes, a preocupação com o atendimento e o serviço pós-venda. Em grande parte das empresas estudadas, notou-se a busca de uma aproximação com o cliente, a exemplo do diretor da empresa $\mathrm{H}$ :

[...] eu não consigo ligar pra todos, a cada noventa dias... eu não consigo fazer isso ainda. Mas eu procuro identificar, dentro das vendas feitas no mês de outubro, por exemplo, pegar 3 clientes de piscina, 3 residenciais, 3 de ... e vamos ligar. Aí nós buscamos esse retorno.

Outro exemplo deste relacionamento está no depoimento da gerente da empresa G:

Às vezes eu saio pra fazer algum serviço de banco, vou visitar algum cliente, as nutricionistas também vão. Quando tem uma empresa grande, as vezes elas vão lá e fazem a refeição com o pessoal no refeitório. Pra analisar o que eles estão achando. [...] Volta e meia a gente faz. Pega, manda fazer uma nega maluca e manda pra eles de tarde pra fazer um lanche. Por que o cliente se sente valorizado, né? Porque a gente lembrou deles. Volta e meia a gente escolhe uns pra fazer isso.

O coordenador de propaganda e promoção da Empresa C citou algumas iniciativas que a empresa está desenvolvendo para melhorar o relacionamento com seus clientes. Embora a empresa $C$ já possui canais de relacionamento que estão vinculados ao sistema de sua franqueadora, de forma bastante efetiva, há um esforço para que este relacionamento seja regionalizado:

Nós estamos desenvolvendo isso, vamos criar (navegação nas) nuvens e também que as nossas agendas de reuniões estejam disponiveis. Quer marcar uma reunião comigo? Você não precisa ligar pra cá, ligar no meu celular, ligar para uma secretária. Você consegue entrar e olhar minha agenda on-line. A gente quer disponibilizar todas essas questões de pesquisa que a gente tem de satisfação, de relacionamento, amor a marca, as nossas campanhas, uma nova musica que a 
franqueadora lança no mercado, campanha de natal e não sabe de onde baixar a musica. A gente quer dar todo esse conteúdo que a gente tem.

Porém, a maioria das empresas ainda utiliza canais de relacionamento mais tradicionais, como é o caso das empresas $A, B, D, E, F$ e G, que basicamente disponibilizam email, telefone e o website da empresa. Ainda assim, o relacionamento com os clientes é bastante valorizado, e estas ferramentas são utilizadas para esse fim. Ressalta-se também a estratégia de participação em feiras de negócios como forma de aproximar-se dos clientes e dos mercados-alvo. Esta estratégia foi observada fortemente nas Empresas B, C, D, G e H.

Tais achados vêm ao encontro dos resultados encontrados pelo IBGE (2010), onde se destaca que os clientes constituem a segunda principal fonte de informação para a inovação na indústria. Destacaram-se, também, as redes de informações, os fornecedores, as áreas internas da empresa e a participação em feiras e exposições, algo também considerado pelas indústrias aqui analisadas.

\subsubsection{Captura de Valor}

Agregar valor ao cliente é, segundo Sawhney, Wolcott e Arroniz (2006), uma forma de inovar descobrindo fluxos de receitas não explorados e proporcionar valor por meio das interações com clientes e parceiros.

Para a maioria das empresas, como são os casos das Empresas A, B, D, E, F e G, a agregação de valor está estritamente relacionada com a busca pela qualidade dos produtos e serviços e com a qualidade do atendimento aos seus clientes. O gerente da empresa $E$ evidencia tal preocupação:

[...] na minha concepção, ela agrega valor ao cliente na maneira como ela atende cada cliente. Pelo menos é o que evidencia isto. Por exemplo, vamos fazer uma inauguração de um mercado. A empresa vai trabalhar em cima de um produto. Tem um técnico que vai pra dentro da loja, passa o dia e faz tudo diferente. Tem pão francês que transforma em trança... Então da todo o suporte ao cliente. $E$ outro exemplo é ouvir o cliente e trabalhar em cima do produto.

As empresas C e D já observam a agregação de valor além da qualidade dos produtos e do atendimento. Nesses casos, o posicionamento da marca e a sua imagem no mercado não bastante valorizado para agregar valor ao cliente e ao negócio. Nesse sentido, o coordenador de propaganda e promoção da Empresa C, evidencia: 


\begin{abstract}
Nós temos produtos que são com um valor agregado muito grande. Um exemplo disso, [Produto $\mathrm{x}$ ], que é uma marca global, uma marca segmentada com alto valor, [Produto y], por ser uma categoria de alto valor, que é a categoria de energéticos da franqueadora, nem se fala. Então a gente procura, com esses produtos, que a gente já tem um valor agregado, coisas que sejam relevantes para o consumidor. Por exemplo, [...] para colocar [Produto $x$ ], o ponto de venda tem que cumprir alguns pré- requisitos. Não podemos colocar em um bar de periferia, pois tem que ter um porta copo, uma bolacha de chopp especial, o chopp tem que ser servido no copo logomarcado desta marca. O banner tem que estar presente e não pode ter um preço agressivo, tem que ter um preço mínimo para ser vendido. Não pode querer vender abaixo do preço de custo, senão bagunça todo mercado, acaba perdendo valor.
\end{abstract}

\title{
4.2.7 Processos
}

De acordo com o modelo de Sawhney, Wolcott e Arroniz (2006), a inovação, nesta dimensão é o redesenho de processos operacionais essenciais para melhorar a eficiência e eficácia.

As empresas analisadas buscaram inovar na melhoria da capacidade produtiva. Isto pode ser evidenciado em todas as empresas, as quais buscam investir em máquinas e equipamentos que proporcionam melhores condições de produtividade e qualidade de seus produtos, bem como relata a empresa A: "[...] sempre procuro melhorar a capacidade das máquinas, investir também em uma máquina que lhe dê melhores condições de produtividade $[. . .]^{\prime \prime}$.

De fato, segundo pesquisa do IBGE (2010), a aquisição de máquinas e equipamentos é considerada a atividade mais relevante para desenvolver suas inovações. Para as indústrias, em especial, o índice chega a $78 \%$ dos casos onde esta atividade é de alta importância para a inovação.

A maior parte das empresas analisadas terceiriza parte de seu processo. Isso se pôde constatar nas empresas $A, C, D, F$ e $H$, sendo que na maioria dos casos, esta terceirização está associada a componentes que não são viáveis financeiramente para as empresas produzirem, conforme relatado pelo diretor da empresa $\mathrm{H}$ :

[...]. algumas coisas terceiriza. Aquilo que achamos que não somos bons, e pra nós chegarmos a ser bom, tem custo alto ou tempo, então vale a pena enviar para um parceiro trabalhar em cima disso e devolver pronto, e a gente pagar por isso. 
No caso das empresas B, E e G, todo processo é feito pela própria empresa. Segundo relato da empresa $\mathrm{E}$ :

Hoje basicamente é feito tudo aqui dentro. Tem uma parte de pães de lanche, mas [...] é ligada ao grupo, e tem toda a produção independente. Ela produz toda a linha de pão de lanche e é autossuficiente, mas é uma padaria que faz parte do grupo.

Em relação à certificação ambiental, deve ser entendida como um instrumento econômico, baseado no mercado, que visa diferenciar produtos oriundos de processos de produção ambientalmente adequados, socialmente justos e economicamente viáveis e fornecer incentivos tanto para consumidores como para produtores (PINTO; PRADA, 1999). Com base no exposto acima, foi identificado que nas empresas $A, B, D, E, F, G$ e $H$ não possuem nenhum manual de boas práticas ou alguma certificação, somente a empresa $C$ que possui a certificação e relata que:

É a gente tem todas as certificações ISO, a gente tem o [Nome do Programa], serviço de qualidade da [Franqueadora], estão sempre acima do que as normativas ISO. exigem, por exemplo: ah, a ISO 14000 de meio ambiente exige que tem que largar $0,0 \ldots$ por $\mathrm{ml}$ quando for que fazer o descarte, a da franqueadora é mais exigente ainda, o nível que a gente tem que largar é muito mais inferior ao que a normativa pede. Então os nossos processos estão todos mapeados acima da normativa. Então a gente tem todas as normativas ISO hoje.

\subsubsection{Organização}

Esta dimensão refere-se à maneira que a empresa busca a melhoria de resultados através da organização. De acordo com o modelo de Sawhney, Wolcott e Arroniz (2006), a inovação, nesta dimensão, muda a forma, função ou escopo de atividade da empresa.

Corroborando, Ferreira (2004) evidencia que as mudanças ocorridas no mercado mundial e, especificamente, no cenário brasileiro levaram nossas empresas a investirem em certos atributos como a confiabilidade, o serviço de pós-venda, produtos ambientalmente corretos e no relacionamento ético da empresa com seus consumidores, fornecedores e varejistas, além de práticas internas relacionadas aos seus funcionários e à preservação do 
meio ambiente. Esse conjunto de mudanças é considerado um componente básico da responsabilidade corporativa.

As empresas analisadas possuem uma estrutura voltada para a inovação. Isto pode ser evidenciado em todas as empresas. A empresa $C$ evidência que:

\begin{abstract}
Ela está voltada a inovação, porque esta estrutura matricial nossa, ela visa o mercado. Então por isso essa agilidade de não ter falando com mil pessoas, de um determinado problema, só falar direto com quem tu acha que vai resolver esse problema. Isso facilita e agiliza o processo. O grande problemas nas grandes empresas é agilizar o processos. E pra fazer qualquer coisa, você depende de duas, ou três pessoas, aqui na fabrica você consegue ir direto nela, nossa matriz é para atender o cliente. Então vem uma demanda do mercado e tu vê que essa pessoa, vai se portar direto a quem vai resolver o problema dela, não vai mais ter que passar pelo chefe, pelo outro setor, não sei quem....
\end{abstract}

Em relação às parcerias, as empresas $A, B, C, D, E, F, G$ e $H$ possuem parcerias para inovar em seus produtos com órgãos públicos, universidades ou fornecedores. Além dessas parcerias, buscam feiras que lhe proporcionem ser uma empresa mais competitiva em relação a seus concorrentes. As empresas $A, B, D, E, F, G$ e H não possuem um canal específico de sugestões, porém relatam que nas reuniões mensais buscam saber dos colaboradores se possuem alguma sugestão. Porém, a empresa $\mathrm{C}$ relata que:

\begin{abstract}
Ela já possuiu, hoje ela não possui mais, nós tínhamos, o "banco de ideias" e nós tínhamos "Compromisso [Nome da franqueadora]", que eram canais de comunicação interna. O banco de ideias, eram soluções novas encontradas pelos funcionários e em cima disse eles ganhavam um percentual da diminuição de custos que essa ideia poderia gerar [....], de coisa que vissem no mercado que não estavam adequadas a nossa estratégia que a gente pudesse informar isso para ser corrigido. Mas isso esta sofrendo uma certa modelagem, vai voltar numa forma de premiação e canal de comunicação hoje [...].
\end{abstract}

Os resultados desta dimensão corroboram com Tidd, Bessant e Pavitt (2001), que percebem a inovação como uma estratégia que não pode ser adotada parcialmente na organização, pois é o resultado de esforços coletivos e contínuos de todas as áreas e não apenas do departamento de pesquisa e desenvolvimento (P\&D).

\title{
4.2.9 Cadeia de fornecimento
}


Esta dimensão relaciona-se com a maneira com que a empresa busca o relacionamento com a sua rede de fornecedores. De acordo com o modelo de Sawhney, Wolcott e Arroniz (2006), a inovação, nesta dimensão, é pensar diferentemente sobre a terceirização e o relacionamento.

Para Mentzer et al. (2001, p. 4), a cadeia de suprimento é “[...] um grupo de três ou mais entidades (organizações ou indivíduos) diretamente envolvidas nos fluxos à montante e à jusante de produtos, serviços, recursos financeiros, e/ou informação da origem ao cliente." As empresas A, B, D, E, F, G e $\mathrm{H}$ analisadas possuem um bom relacionamento com seus fornecedores, buscando reduzir as distâncias, tanto de custos de transportes, estoque e de matéria-prima. A empresa $\mathrm{C}$ inovou ao buscar reduzir custos através de compra via leilão, em parceria com outras franqueadas da marca, e possui uma empresa do grupo situada em outro estado devido à tributação mais baixa:

[...] essa questão de compra via leilão, é a economia em escala, essa economia de transporte, como a gente importa o pet, a gente viu que era mais barato, mas vantajoso a gente criar uma empresa de exportação em Santa Catarina, com incentivo, fiscal, importarmos ele até Santa Catarina, trazermos ele de volta para Santa Maria e produzir aqui. Não é só tramite de nota, é tramite de carga toda. Ela vem lá do Uruguai, passa por Santa Maria, segue para Santa Catarina, ela faz reemissão de nota [...] e volta pra cá. Nessa brincadeira a gente economiza muito dinheiro, do que nós importarmos direto pra Santa Maria... Sim, tributação e incentivos fiscais lá, e vale a pena ser lá, em função disso a gente teve um outra oportunidade, que essa empresa ela vai começar a fornecer para outras fornecedoras [...], para não ter que importar do Uruguai pet, então porque não importar por esse empresa que importa com uma condição melhor de preço. Então é coisas que eles foram vendo dentro do processo, como eles poderiam se adequar, reduzir custos em função disso, né.

\subsubsection{Presença}

Esta dimensão está relacionada como a empresa utiliza os canais de distribuição e quais os canais de venda que a empresa possui. De acordo com o modelo de Sawhney, Wolcott e Arroniz (2006), inovar, nesta dimensão, consiste em criar novos canais de distribuição ou pontos de presença inovadoras, incluindo os lugares onde as ofertas podem ser compradas ou utilizadas pelos clientes. 
As empresas A, B, C, E e $\mathrm{H}$ possuem representantes que atuam em algumas regiões estratégicas que realizam os pedidos e o produto chega ao cliente, buscando manter contato direto através de e-mails e telefone.

A Empresa C busca inovar nesta dimensão na criação de novos canais de vendas, que normalmente não são considerados pontos de venda de bebidas, conforme afirma o coordenador de propaganda e promoção da empresa:

\begin{abstract}
Tem novas. A gente chama de canais emergentes, que é o nome que a gente deu, que são canais que, porque eles não podem vender bebidas, são lojas, drogarias, farmácias, a gente agora conseguiu com a ANVISA a liberação da comercialização. Lotéricas, salões de estéticas, escritórios, então são diversos canais que a gente vê, tem pessoas que circulam que consomem bebidas, são canais que tem fluxo de pessoas, e porque não ter a venda de [Marca franqueada] lá? E então, colocamos o que a gente chama de canais emergentes, uma coisa relativamente nova, pra gente a pouco tempo. Nós tivemos que desenvolver pra drogarias, nós desenvolvemos uma adesivagem especial para eles que é toda verde, ao invés de vermelha para se adequar ao que é uma drogaria [...]. Quando é menor, lotérica, salão de beleza, a gente não pode colocar um geladeira igual que tem no supermercado, a gente colocou o que a gente chama de [nome], é uma geladeirinha que é metade do frízer da [marca de sorvete], aquela geladeirinha pequeninha, porque a quantidade que eles vão vender não vai ser grande, e se somar todas as lotéricas da cidade, somar todos os salões de beleza, todas as lojas, tem lojas de roupas que tem nossas geladeiras.
\end{abstract}

Já a empresa $\mathrm{F}$ possuía representantes em várias regiões, mas, ultimamente, a venda tem sido diretamente com o cliente. Na empresa G, a venda é realizada direto com o cliente, não possui representantes. A empresa $D$ busca manter o contato, tanto através de representantes com o cliente, como do seu diretor, que procura abordar tanto com o varejista como o cliente final (consumidor), relatando que:

[...] esses dias eu estava em Santa Rosa/RS, "mas tu vem visitar o mercadinho pequeninho que nem o meu?", eu disse: se o senhor compra [Marca D] então o senhor é importante para nós" né então assim. Se comprar um pacote, dois ou mil, dez mil o senhor ta comprando [Marca D], pra nós é importante. Então tu mantêm isso né com os clientes sabe, dá um trabalho danado rsrsr, tu tem que ter vontade. Eu saio daqui, as vezes venho aqui às 10 horas da manhã, vou a Chapecó, e antes disso eu passo em Sarandi, passo na cooperativa [X], dá uma faladinha com o gerente, passo no outro mercado lá dou uma faladinha com $[X]$, né depois vou em Nonoai falo com o e as vezes chego lá em Chapecó $3 \mathrm{~h}$ da tarde e já vou direcionado pra falar com um ou com outro, entendeu. Então vou lá falo com as pessoas, coisa e tal e mantenho esse relacionamento, bah acho que perdi a viagem, 
e tu vai te analisando na volta, tu sente andar 4 a 5 horas e depois voltar 5 horas. Esses dias sai de Nonoai pra cá 11 horas da noite, 11:30 chego as 3 horas da manhã.

\subsubsection{Rede de relacionamento (Networking)}

Esta dimensão está relacionada à maneira como a empresa possui relação com os seus stakeholders, como a empresa gerencia essa rede de relacionamentos. De acordo com o modelo de Sawhney, Wolcott e Arroniz (2006), a inovação, nesta dimensão, cria uma rede integrada de ofertas.

As empresas A, B, C, D, G e H buscam manter contato, por meio de telefone e $e$ mail, e procuram sempre manter a comunicação com seus clientes. Com os demais stakeholders, foram indicadas algumas ações pontuais, principalmente com fornecedores e órgãos públicos.

A empresa F gerencia conforme a necessidade de cada ocasião. Já a Empresa $E$, relata que não possui essa relação com as partes interessadas de forma estruturada:

[...] não tem nada gerenciando esse tipo de coisa, na realidade, nem metas. Vai conforme participação de feiras, eventos... não há nada gerenciando...mas existir, existe, diretores que possuem relacionamentos departamento comercial, contatos, feiras, concorrentes.

\subsubsection{Marca}

Esta dimensão está relacionada a como a empresa gerencia a sua marca em relação ao seu posicionamento no mercado. De acordo com o modelo de Sawhney, Wolcott e Arroniz (2006), a inovação, nesta dimensão, eleva a marca na busca de novos mercados.

Todas as empresas entrevistas possuem preocupação com a proteção da sua marca e, desta forma, possuem uma marca registrada. A empresa A, segundo o sócio, está em um setor que não exige o conhecimento da sua marca e sua estratégia é voltada à relação com o cliente. $A$ empresa $B$, ampliou o uso de sua marca, utilizando-a em outro segmento: 
Já a empresa C, realizada um trabalho de marca diferenciado. Isto porque possui a sua marca local, utilizada como uma submarca, além de utilizar todas as marcas globais pertencentes à sua franqueadora, com um forte trabalho de comunicação sobre essas, direcionando-as para cada público-alvo. Segundo o coordenador de promoção e propaganda da empresa, por vezes, o público acaba confundindo as marcas, associando à indústria somente a marca principal da franqueadora. Em função disto, a empresa busca um fortalecimento de sua marca local e, recentemente, fez modificações modernizando-a. A empresa busca futuramente abranger a sua marca para outros segmentos, relatando que:

[...] é que a gente não tem ainda novos negócios, nós estamos em negociações, com outras empresas, ainda a gente não tem um novo negocio para estar usando ela, mas quando nós tivermos ela vai vim como assinatura ou subassinatura, [...].

\subsection{Aspectos complementares}

Com o objetivo de incrementar os resultados apresentados, possibilitando um enriquecimento de informações em relação à inovação nas organizações estudadas, esta seção apresenta características observadas nas empresas, bem como opiniões dos entrevistados em relação à inovação em suas organizações.

Inicialmente, destaca-se que a percepção sobre inovação entre os entrevistados não se limitou à oferta de novos produtos ou somente à tecnologia. De acordo com o coordenador de propaganda e promoção da Empresa C, a inovação envolve diversos aspectos:

Para mim inovação é sempre estar buscando uma forma nova de interagir com o mercado, pode ser ele nossos fornecedores ou os nossos clientes ou nossos consumidores. Pra mim é isso é não se resumiria somente a tecnologia, acho que é uma forma de atuar, em todos os ramos e segmentos.

Em relação às vantagens proporcionadas pela inovação nestas indústrias, todas as empresas evidenciaram o impacto positivo em decorrência de atividades inovativas. Em geral, segundo os entrevistados, a inovação traz benefícios de produtividade, competitividade, eficiência, qualidade, participação de mercado, redução de custos entre outros aspectos. Além disso, alguns entrevistados afirmaram que é dada uma importância 
muito grande para a inovação, embora, por vezes, os seus benefícios não sejam mensuráveis no curto prazo, conforme o sócio da Empresa A:

\begin{abstract}
Em termos de percentual 100\% (importância). Hoje em dia em questão de produtividade, a inovação proporciona isso. Nós realizamos um investimento de 500 mil reais em maquinário, que oferece produtividade. [...] Então com isso tem um ganho de produtividade e redução de custos. A inovação tecnológica é uma necessidade. [...] Isso pode não resultar, não ver um resultado, enfim, imediato. Mas a médio e longo prazo, com certeza. Então é como uma sementinha, você planta hoje e cresce uma coisa a mais, seja qualidade, seja atendimento. A inovação envolve tudo. Eu considero muito importante.
\end{abstract}

Tais evidências corroboram com os achados do IBGE (2010) que destacam como principais impactos positivos da inovação o aumento ou manutenção da participação de mercado, melhoria da qualidade dos bens e serviços e melhorias no processo, respectivamente, os quais todos foram citados pelas empresas participantes desta pesquisa.

Segundo um dos entrevistados, embora a inovação, de uma maneira geral, traz resultados positivos, por outro lado pode trazer resultados diferentes dos esperados. Para a gerente da Empresa G, o impacto da inovação nem sempre é positivo em uma empresa:

\footnotetext{
Nem sempre. Por que as vezes eu acho que a coisa ta boa, ta andando bem. As vezes uma alteração pode sofre uma ruptura muito grande. E agente tem aqui gente de todas as idades. E tem pessoas que são reticentes à mudança. Então a gente sofre também com isso. É uma coisa que é muito cautelar. "Ah...nós vamos mudar tudo". Não é assim.
}

Entre os aspectos complementares, destacam-se as dificuldades encontradas pelas empresas no processo de inovação. A resistência à mudança, conforme citado anteriormente, está entre as principais dificuldades, segundo os entrevistados. De acordo com os representantes das empresas A, C, D, E, G e H, a resistência cultural das pessoas, tanto internamente como no mercado, é um dos fatores limitadores da inovação. O diretor da empresa $\mathrm{H}$ relata sobre a resistência no mercado em relação à oferta de produtos novos:

A inovação é uma linha bem tênue do quanto se tem que inovar, e do quanto se tem que ser conservador, em função da resistência que se tem. Se você for muito inovador, você não sobrevive. Se você for muito conservador, acaba se 
desatualizando e fica pra trás. [...] Então, tem aí um ponto bem... isso não só a Empresa $\mathrm{H}$, eu to falando geral.

Corroborando, o coordenador de propaganda e promoção da Empresa C também cita a resistência das pessoas e acrescenta uma outra dificuldade: os fatores envolvidos do desenvolvimento e maturação de uma inovação:

\footnotetext{
Eu acho que tem duas coisas, que é a cultural, que depende da pessoa, do setor, da coisa que tu quer colocar essa inovação, tem uma certa resistência, tem que quebrar uma certa barreira. Tem também o prazo, a questão de pesquisa para essa inovação, se ela realmente vai dar resultado, qual é o valor que tu vai gastar com a inovação, ou então as pessoas que você vai ter que envolver para desenvolver essa inovação. Tem também as vezes o time, nem sempre é o mais adequado pra isso, eu acho que seria essas duas. Quebra de barreiras culturais de pessoas e a questão do prazo e do planejamento.
}

Outra dificuldade enfrentada pelas empresas para a implementação da inovação é a disponibilidade de recursos. O limite financeiro foi citado como fator primordial em quatro das oito empresas (empresas A, B, E e F), conforme a afirmação do consultor da empresa F: "Pra mim a única dificuldade é financeira. Financeira. Onde tiver recurso financeiro para inovar, fazer coisas novas, produtos novos, não vai existir dificuldades. Enquanto o financeiro não limitar a engenharia, a gente faz qualquer negócio."

Por fim, procurou-se relacionar, a partir de uma análise comparativa, o grau de inovação nas indústrias com as suas características, como o porte da empresa e o tempo de mercado, conforme verificado no estudo do IBGE (2010), que evidenciou associação positiva das taxas de inovação e o porte da empresa. Porém, não foi possível identificar, qualitativamente, tais evidências. Isto porque, identificou-se, por exemplo, um grau de inovação bastante elevado na empresa C, uma empresa de grande porte, que conta com 750 colaboradores e 31 anos de mercado, bem como na empresa $\mathrm{H}$, microempresa com somente 4 anos de funcionamento e apenas 19 colaboradores. Neste sentido, sugere-se, para estudos futuros, uma análise quantitativa, através de um levantamento, com o objetivo de identificar tais relações.

A partir dos resultados acima apresentados, pôde-se perceber a aplicação da inovação nas indústrias estudadas, de acordo com as 12 dimensões propostas no modelo 
conceitual. Além disso, foi possível identificar os impactos provocados em cada empresa, a importância dada pelos gestores e as dificuldades enfrentadas por eles. A partir dessas avaliações, pode-se tecer as considerações finais do estudo e consolidar os resultados obtidos na pesquisa.

\section{CONSIDERAÇÕES FINAIS}

Este estudo foi desenvolvido com o objetivo de identificar atividades inovadoras em indústrias do Distrito Industrial de Santa Maria/RS e possibilitou, através dos resultados apresentados, o conhecimento da realidade desta temática nas empresas pesquisadas. Através do estudo das 12 dimensões propostas por Sawhney, Wolcott e Arroniz (2006), pôde-se verificar a inovação em oito indústrias, classificadas de microempresa à grande empresa, dos mais variados ramos de atividades e tempo de atuação no mercado, o que, sem dúvida enriqueceu este estudo.

Destaca-se a importância do estudo deste tema, em especial, para as indústrias estudadas. A inovação é, conforme Motta (2001), uma estratégia fundamental para a competitividade das empresas.

Os resultados descritos anteriormente permitiram uma análise detalhada sobre cada uma das dimensões estudas. Assim, pôde-se perceber que algumas empresas apresentam determinadas características de inovação que as diferem das demais. A partir deste panorama, as empresas foram classificadas, conforme grau de inovação em cada uma das variáveis, como proposto por Sawhney, Wolcott e Arroniz (2006). Deve-se considerar que essa classificação foi realizada de forma comparativa entre as empresas, por meio de evidências observadas. Dessa forma, na Figura 1, a seguir, estão apresentadas as doze dimensões da inovação nas empresas pesquisadas. Optou-se por separar em dois gráficos para permitir melhor visualização. 
Figura 1 - As doze dimensões da inovação nas empresas pesquisadas

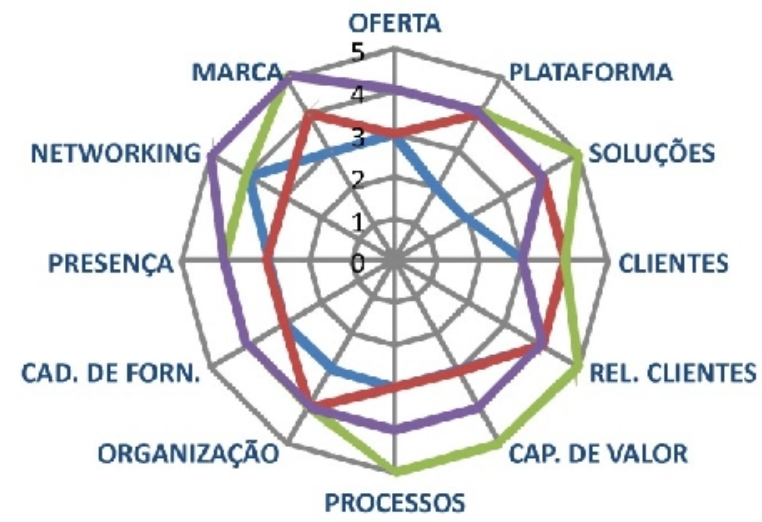

$\longrightarrow \mathrm{A}-\mathrm{B}-\mathrm{C}=\mathrm{D}$

Fonte: Elaboração dos autores, 2013.

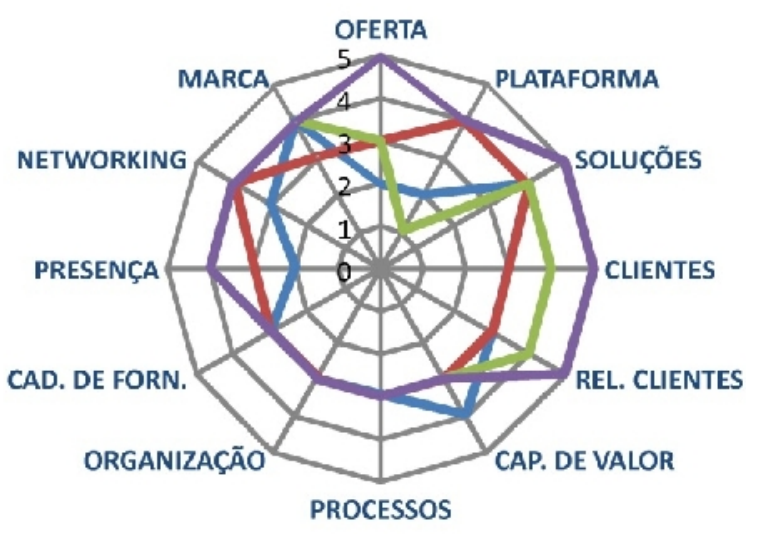

$\longrightarrow \mathrm{E} \longrightarrow \mathrm{F} \longrightarrow \mathrm{G} \longrightarrow \mathrm{H}$

Ressalta-se que esta pesquisa possui limitações. Entre elas, está o fato de tratarse de um estudo de casos múltiplos. Neste sentido, os resultados aqui apresentados referem-se às empresas que participaram desta pesquisa, impossibilitando a inferência destes para as demais indústrias situadas no Distrito Industrial de Santa Maria/RS.

Por fim, destaca-se que o estudo apresenta contribuições relevantes, visto que a análise qualitativa utilizada permitiu maior detalhamento das práticas inovativas nas indústrias selecionadas. Pôde-se perceber, também, de forma bastante clara, evidências de atividades inovadoras em cada uma das dimensões propostas no modelo conceitual.

\section{THE INNOVATIVE ACTIVITY IN INDUSTRIES OF SANTA MARIA/RS: A MULTICASE STUDY}

\section{ABSTRACT}

This study aims at identifying the innovative maturity in industries sited in the industrial district of Santa Maria/RS, Brazil. To this end, was developed a descriptive research, qualitative approach, through a multi-case study. It was used the framework proposed by Sawhney, Wolcott and Arroniz (2006), called the Innovation Radar, which addresses the opportunities for innovation in twelve dimensions: Offerings, platform, solutions, costumers, costumer experience, value capture, process, organization, supply chain, presence, networking and brand. It was identified the presence of innovative practices in all 
dimensions proposed in the conceptual model, and it was possible to see how is the development of such activities in each of the companies studied. Moreover, it was verified the importance of innovation to these industries and the difficulties they face in this process.

Keywords: Innovation. Industry. Innovative Maturity.

\section{REFERÊNCIAS}

ASSOCIAÇÃO DISTRITO VIVO. Website. Santa Maria, 2011. Disponível em: < http://www.distritovivo.org.br/home.asp>. Acesso em: 30 out. 2011.

BANCO NACIONAL DE DESENVOLVIMENTO ECONÔMICO E SOCIAL - BNDES. Circular no 34, de 06 de setembro de 2011. 2011. Disponível em:

<http://www.bndes.gov.br/SiteBNDES/export/sites/default/bndes_pt/Galerias/Arquivos/pr odutos/download/Circ034_11.pdf>. Acesso em: 12 jan. 2012.

BACHMANN, D. L.; DESTEFANI, J. H. Proposal for Assessment of Innovation Degree at Small Companies, 2008, Aracaju SE. Anais do XVIII Seminário Nacional de Parques Tecnológicos e Incubadoras de Empresas, 2008.

BESSANT, J; TIDD, J. Inovação e empreendedorismo. Porto Alegre: Bookman, 2009.

CHRISTENSEN, C. O dilema da inovação. São Paulo: Makron Books, 2001.

COFFEY, A.; ATKINSON, P. Making sense of qualitative data: complimentary research strategies. Londres: SAGE Publications, 1996.

DAMANPOUR, F. Organizational innovation: a meta-analysis of effects of determinants and moderators. Academy of Management Journal, v. 34, n. 3, p. 555-590, 1991.

FERREIRA, R. N. Responsabilidade social, governança corporativa e valor das empresas. O.R. \& A. Revista de Administração da UFLA, v. 6, n.1, 132, janeiro/junho 2004.

GIL, A. C. Como elaborar projetos de pesquisa. 4. ed. São Paulo: Atlas. 2007.

GODOY, A. S. Pesquisa qualitativa: tipos fundamentais. Revista de Administração de Empresas - RAE. v.35, n.3, p. 20-29. 1995.

GOMES, C. M.; KRUGLIANSKAS, I. Indicadores e características da gestão de fontes externas de informação tecnológica e do desempenho inovador de empresas brasileiras. RAC v. 13, n. 2, p. 172-188, abr./jun. 2009. 
IBGE. Instituto Brasileiro de Geografia e Estatística. Pesquisa de inovação tecnológica 2008 PINTEC. Rio de Janeiro, 2010.

KEMP, R; SMITH, K; BECHER, G. How should we study the relationship between environmental regulation and innovation? In: European Commission JRC-IPTS and Enterprise DG. The impact of EU regulation on innovation of European Industry. 2000. Disponível em: <http://ftp.jrc.es/EURdoc/eur19827en.pdf>. Acesso em: 11 jul. 2011.

KRUGLIANSKAS, I. Tornando a pequena e média empresa competitiva. São Paulo: Instituto de Estudo Gerenciais e Editora, 1996.

MANUAL DE OSLO. Diretrizes para coleta e interpretação de dados sobre inovação. 3. ed. 2005. Disponível em: <http://www.finep.gov.br/dcom/brasil_inovador/capa.html>. Acesso em: 11 jun. 2011.

MENTZER, J et al. Defining Supply Chain Management. Journal of Business Logistics, v. 22, n. 2, p. 1-25, 2001.

MOTTA, P. R. Transformação organizacional: a teoria e a prática de inovar. Rio de Janeiro: Qualitymark, 2001.

OCDE. Organização de Cooperação e de Desenvolvimento Econômico. Sustainable Manufacturing and Eco innovation: Towards a Green Economy. Policy Brief, June, 2009.

PINTO, L. F.G., PRADA, L. de S. Certificação agrícola socioambiental: iniciativa piloto para a cana-de-açúcar. Revista informações econômicas. São Paulo, v. 29, n. 5, p.19-29, 1999.

RICHARDSON, R. J. Pesquisa social: métodos e técnicas. 3. ed. São Paulo: Atlas, 1999.

SAWHNEY, M; WOLCOTR, R; ARRONIZ, I. The 12 Different Ways for Companies to Innovate. MIT Sloan Management Review. p. 75-81, spring 2006.

SCHUMPETER, J. A. A teoria do desenvolvimento econômico. São Paulo: Cultural, 1985.

SUGAHARA, C. R.; JANNUZZI, P de M. Estudo do uso de fontes de informação para inovação tecnológica na indústria brasileira. Ci. Inf. v. 34, n. 1, p.45-56, jan./abr. 2005.

TIDD, J., BESSANT, J., PAVITT, K. Managing innovation: integrating technological, market and organizational change. West Sussex: John Wiley \& Sons, 2005.

TRIVIÑOS, A. N. S. Introdução à pesquisa em ciências sociais: a pesquisa qualitativa em educação. São Paulo: Atlas, 1987.

YIN, R. K. Estudo de Caso: planejamento e método. 2. ed. São Paulo: Bookman, 2001. 